\title{
BMJ Open Lay knowledge of cardiovascular disease and risk factors in three communities in Accra, Ghana: a cross- sectional survey
}

\author{
Olutobi Adekunle Sanuade (10 , ", Mawuli Komla Kushitor, ${ }^{2}$ Raphael Baffour Awuah, ${ }^{3}$ \\ Paapa Yaw Asante, ${ }^{4}$ Charles Agyemang, ${ }^{5}$ Ama de-Graft Aikins ${ }^{6}$
}

To cite: Sanuade $O A$, Kushitor MK, Awuah RB, et al. Lay knowledge of cardiovascular disease and risk factors in three communities in Accra, Ghana: a crosssectional survey. BMJ Open 2021;11:e049451. doi:10.1136/ bmjopen-2021-049451

- Prepublication history for this paper is available online. To view these files, please visit the journal online (http://dx.doi. org/10.1136/bmjopen-2021049451).

Received 25 January 2021 Accepted 05 November 2021

Check for updates

(C) Author(s) (or their employer(s)) 2021. Re-use permitted under CC BY-NC. No commercial re-use. See rights and permissions. Published by BMJ.

${ }^{1}$ Department of Preventive Medicine, Northwestern University Feinberg School of Medicine, Chicago, Illinois, USA ${ }^{2}$ Department of Health Policy, University of Health and Allied Sciences, Ho, Ghana

${ }^{3}$ Regional Institute for Population Studies, University of Ghana,

Legon, Ghana

${ }^{4}$ Department of Psychology, University of Ghana, Legon, Ghana

${ }^{5}$ Academic Medical Centre, University of Amsterdam, Amsterdam, The Netherlands

${ }^{6}$ Institute of Advanced Studies, University College London, London, UK

Correspondence to

Professor Ama de-Graft Aikins; a.de-graft-aikins@ucl.ac.uk

\section{ABSTRACT}

Objectives Cardiovascular disease is a major cause of morbidity and mortality in Ghana, and urban poor communities are disproportionately affected. Research has shown that knowledge of cardiovascular disease (CVD) is the first step to risk reduction. This study examines knowledge of CVD and risk factors and determinants of CVD knowledge in three urban poor communities in Accra, Ghana.

Methods Using the Cardiovascular Disease Risk Factors Knowledge Level Scale, which has been validated in Ghana, we conducted a cross-sectional survey with 775 respondents aged 15-59 years. CVD knowledge was computed as a continuous variable based on correct answers to 27 questions, and each correct response was assigned one point. Linear regression was used to determine the factors associated with CVD knowledge. Results The mean age of the participants was $30.3 \pm 10.8$ years and the mean knowledge score was $19.3 \pm 4.8$. About one-fifth of participants were living with chronic diseases. Overall, $71.1 \%$ had good CVD knowledge, and $28.9 \%$ had moderate or poor CVD knowledge. CVD knowledge was low in the symptoms and risk factor domains. A larger proportion received CVD knowledge from radio and television. The determinants of CVD knowledge included ethnicity, alcohol consumption, self-reported health and sources of CVD knowledge. CVD knowledge was highest among a minority Akan ethnic group, those who were current alcohol consumers and those who rated their health as very good/excellent, compared with their respective counterparts. CVD knowledge was significantly lower among those who received information from health workers and multiple sources.

Conclusion This study underscores the need for health education programmes to promote practical knowledge on CVD symptoms, risks and treatment. We outline health systems and community-level barriers to good CVD knowledge and discuss the implications for developing context-specific and culturally congruent CVD primary prevention interventions.

\section{BACKGROUND}

Cardiovascular disease (CVD) is a major cause of death globally. ${ }^{1}$ Low and middle-income countries (LMICs) are disproportionately affected because more than three-quarters
Strengths and limitations of this study

- This study enrolled individuals living in three urban poor communities in Accra, Ghana.

- We adopted a cross-sectional design, using the Cardiovascular Disease Risk Factors Knowledge Level Scale, to understand level and determinants of cardiovascular disease (CVD) knowledge.

- A limitation of our study is that the CVD knowledge scale that we adopted has an imbalance between scale-item weight and the incidence of existing risk factors of CVD in Ghana.

- Another limitation is that participants' responses on sources of CVD knowledge may have been affected by recall bias.

of global deaths occur in these regions. ${ }^{2}$ By 2020, it is projected that CVD mortality will increase by $120 \%$ for women and $137 \%$ for men; by 2030, almost 23.6 million people will die from CVD, mainly from heart disease and stroke. $^{2-5}$ In Ghana, CVD is a major cause of death and accounts for as high as one-fifth of all causes of death. ${ }^{6}$

Research shows that small reductions in risk factors at the population level translate into substantial reductions in CVD events and deaths. ${ }^{7-9}$ Population-based intervention approaches reduce the burden of CVDs and close the gap in CVD burden between highincome and low-income area. ${ }^{10}$ Effective population-based approaches to CVDs have the potential to reduce the number of people who require drug treatment. ${ }^{11}{ }^{12}$ Primary intervention strategies, such as public health education, are critical to reduce the incidence and prevalence of CVD. ${ }^{13-15}$

Research has shown that lay knowledge of risk factors of diabetes, hypertension and stroke is poor in many countries, ${ }^{13-17}$ including Ghana. ${ }^{1819}$ This partly leads to poor management and treatment outcomes such 
as delay in presentation to hospital for early diagnosis and treatment, ${ }^{17}$ high case fatality rate ${ }^{20}$; under diagnosis and high rates of disability ${ }^{16}$; high incidence of $\mathrm{CVD}^{20}$ and premature deaths. ${ }^{16}$ Promoting CVD knowledge is, therefore, important because it is the first step to risk reduction across global communities. ${ }^{1620}$ A few studies that have been carried out in urban poor communities in Accra, Ghana have shown high CVD prevalence rates, ${ }^{18} 19$ and these rates are higher than in the general population. Since knowledge of CVD is a first step for enhancing primary prevention, it is, therefore, important to examine what people know about CVD in these communities. This study examines knowledge of CVD and risk factors and determinants of CVD knowledge in three urban poor communities in Accra, Ghana.

\section{METHODS}

\section{Study design}

This was a cross-sectional study. We used the Strengthening the Reporting of Observational Studies in Epidemiology cross-sectional checklist when writing our report. ${ }^{21}$

\section{Study setting}

The study was conducted in Agbogbloshie, James Town and Ussher Town. All three communities are located in the Ashiedu Keteke submetropolis of the Accra Metropolitan Assembly and are close to the central business district. ${ }^{22}$ Agbogbloshie is a migrant multiethnic community and many of the residents lack access to formal healthcare, clean water, sanitation and live in makeshift housing structures. Many of the inhabitants work as traders and artisans. ${ }^{22}$ James Town and Ussher Town are indigenous $\mathrm{Ga}$ communities and have relatively better access to healthcare with a government health facility (ie, Ussher Town Polyclinic), which serves both communities. The main economic activities in these two communities are fishing and petty trading. ${ }^{19}$ All the three communities are characterised by high population density and low socioeconomic status with an average monthly income of 126.13 Ghana Cedis (US\$28.6; 2011).$^{19}$ Although about three quarters have attained up to Junior High School (or middle school) and above, the quality of education is generally low due to the dominance of poorly resourced public schools in these communities. Previous studies have shown the high prevalence of hypertension in these three communities, with low levels of awareness, treatment and control. ${ }^{18}$

\section{Sampling technique and sample size}

This study was part of a broader longitudinal study called the 'Urban Health and Poverty Project' conducted by the Regional Institute for Population Studies with support from the African Caribbean and Pacific Group of StatesACP-EU Cooperation Programme in Higher Education (EDULINK) and International Development Research Centre. The aim of EDULINK was to understand the inequalities in health and human welfare of the people living in these communities over time. Three waves of the Urban Health and Poverty project were conducted at approximately 18-month intervals in 2010 (June), 2011 (December) and 2013 (August) with households and individuals. The third survey round conducted between August and September 2013 was used in this study. A total of 775 respondents aged 15-49 years were randomly selected for the third wave, and this formed the sample for this study.

The sampling design followed a two-stage sampling. The first stage involved random selection of enumeration areas (EAs) proportionate to the population sizes of the three localities. A total of 5 EAs were selected from Agbogbloshie, 8 from James Town and 16 from Ussher Town. After this, all the structures in the sampled EAs were numbered and a household listing exercise was conducted. Households on the list were cumulated, and this constituted the sampling frame. The second stage was based on systematic sampling of forty households from each of the $29 \mathrm{EAs}$, and this resulted in a total of 1160 sampled households. All household members in their reproductive ages (between 15-59 years for men and 15-49 years for women) were eligible for interviews. Details of the sampling procedure have been provided elsewhere. ${ }^{22}$

\section{Measures}

\section{Cardiovascular disease knowledge}

We adapted the Cardiovascular Disease Risk Factors Knowledge Level scale developed by Arikan et al ${ }^{23}$ and which had been validated in the urban Ghanaian context. ${ }^{24}$ The knowledge scale consists of 27 items (table 1). The first 19 items focused on the risk factors of CVD; items 20 and 21 addressed CVD symptoms and items 22 to 27 focused on CVD prevention, treatment and control. Items 8, 16 and 27 were negatively worded and these were recoded in the analyses. The items in the scale were presented to the participants in a truefalse question format composed of full sentences. The participants were asked to answer 'yes', 'no' or 'i don't know' to each item. Every 'correct answer' corresponded to 1 point, and every 'wrong answer' or 'I don't know' corresponded to 0 point. The scale has a high internal consistency coefficient (Cronbach's alpha) of 0.81 and has been shown to have good indices of validity. ${ }^{23}$ Scores were also expressed in percentages. Score of $<50 \%$ was classified as poor CVD knowledge, between $50 \%$ and $69 \%$ as moderate CVD knowledge and score $\geq 70 \%$ as good CVD knowledge. ${ }^{25}$

\section{Chronic diseases}

Respondents who had been diagnosed with any of the following conditions were coded as living with a chronic disease: arthritis, asthma, diabetes, heart disease, high blood cholesterol, hypertension, kidney disease and stroke. 
Table 1 Cardiovascular disease risk factors knowledge

\begin{tabular}{ll}
\hline & Items \\
\hline & CVD risks \\
\hline 1 & Heart disease can be prevented \\
\hline 2 & Cigarette smoking can cause heart disease and stroke \\
\hline 3 & There is greater risk for heart disease in elderly \\
4 & $\begin{array}{l}\text { People with high blood pressure should avoid salt in their } \\
\text { diets. }\end{array}$ \\
\hline 5 & If people quit smoking it reduces the risk of heart disease \\
\hline 6 & Salty food makes causes high blood pressure \\
\hline 7 & High blood pressure is a risk factor for heart disease \\
\hline 8 & Fatty foods do not increase blood cholesterol levels \\
9 & $\begin{array}{l}\text { More than three meals per week of red meat are not good for } \\
\text { your health }\end{array}$
\end{tabular}

\begin{tabular}{|ll}
\hline 10 & Eating fruit and vegetables every day is beneficial \\
11 & Overweight people are more likely to have heart disease \\
12 & Regular exercise reduces risk of heart disease \\
13 & Regular walking can reduce risk of heart disease \\
14 & Stress and sadness increase the risk of heart disease \\
15 & Under stressful situations, blood pressure will increase \\
17 & Heavy alcohol use does not affect your blood pressure. \\
\hline 18 & Diabetes is a risk factor for heart disease \\
19 & $\begin{array}{l}\text { Heart disease in your family will increase your risk of heart } \\
\text { disease }\end{array}$
\end{tabular}

CVD symptoms

20 Shortness of breath may be a sign of heart disease.

21 Feeling chest pain or discomfort can be a sign of heart disease

CVD prevention, treatment and control

\begin{tabular}{|c|c|}
\hline 22 & $\begin{array}{l}\text { To keep blood pressure under control will reduce the risk of } \\
\text { heart disease }\end{array}$ \\
\hline 23 & $\begin{array}{l}\text { People with high blood pressure need to use blood pressure } \\
\text { medicine for life }\end{array}$ \\
\hline 24 & People with high cholesterol need to take medication \\
\hline 25 & People with diabetes need to control sugar intake \\
\hline 26 & $\begin{array}{l}\text { People should only get their blood pressure checked if they } \\
\text { have chest pain or headaches }\end{array}$ \\
\hline 27 & $\begin{array}{l}\text { If you have high blood pressure taking a medicine for } 1 \text { month } \\
\text { can cure you }\end{array}$ \\
\hline
\end{tabular}

Source: Arikan et al.

CVD, cardiovascular disease.

\section{Sources of knowledge}

The questions on sources of knowledge were multiple response scale and participants were supposed to state if they had heard of CVD from each of the following sources: television, radio, friends/relatives, schools/ teachers, health workers and other sources (eg, pamphlets/posters, newspaper/magazines, community meetings, mosques/churches, drama/performance and work place). The multiple responses were recategorised into a single variable (with seven categories) called 'sources of knowledge'. The categories for the sources of knowledge variable were: television, radio, friends/relatives, schools/teachers, health workers other sources and multiple sources.

\section{Physical activity}

Physical activity was measured as the number of days respondents spent doing moderate-intensity activities including sports, fitness or recreational leisure activities. We recategorised these into three: physically inactive, partially active (those engaged in physical activities less than three times a week) and fully active (those who engaged in physical activities three or more times a week. ${ }^{26}$

\section{Smoking, alcohol consumption and self-rated fat intake}

The question on smoking focused on whether participants currently use (smoke, sniff or chew) any tobacco products such as cigarettes, cigars, pipes, chewing tobacco or snuff at the time of the survey. Those who responded 'yes' were coded as 'smokers' and those who responded 'no' were coded as 'non-smokers'. The question on alcohol consumption focused on consumption of any alcoholic drink in the 30 days prior to the survey. The responses were 'yes' (if a participant consumed alcohol in the 30 days prior to the survey) and 'no' (if a participant did not consume alcohol in that time). For self-rated fat intake, participants were asked to rate the level of fat in their diet over the past 12 months prior to the survey, and the responses were low, medium and high. Previous studies have shown that self-rated fat intake is a valid measure for evaluating diet quality at the population and it also provides a simple method for identifying people with worst diet quality. ${ }^{27} 28$

\section{Sociodemographic variables}

Sociodemographic variables included in the analysis were sex, age, level of education, religion, locality, occupation, marital status and ethnicity.

\section{Data analysis}

Means and SD were used to summarise continuous variables and frequency distributions were used to summarise categorical variables. We used multiple linear regression to examine the predictors (sociodemographic characteristics, chronic diseases, physical activity, alcohol consumption, smoking, self-rated fat intake and sources of CVD knowledge) of CVD knowledge and the significant levels were set at $\mathrm{p}<0.05, \mathrm{p}<0.01$ and $\mathrm{p}<0.001$. The variables included in the multivariable analysis and their corresponding reference categories were theoretically selected based on previous studies. For instance, previous studies showed that older people have more CVD knowledge compared with youths; hence, we made the youths (15-24 years) the reference category. The data were analysed using STATA V.12.

\section{Patient and public involvement}

Patients were not involved at any stage of the research for this study. 


\begin{tabular}{|c|c|c|}
\hline Characteristics & Number & Percentage \\
\hline \multicolumn{3}{|l|}{ Sex } \\
\hline Male & 341 & 44.0 \\
\hline Female & 434 & 56.0 \\
\hline \multicolumn{3}{|l|}{ Level of education } \\
\hline No education & 54 & 7.0 \\
\hline Primary & 128 & 16.5 \\
\hline Middle/JHS & 331 & 42.7 \\
\hline Secondary/higher & 262 & 33.8 \\
\hline \multicolumn{3}{|l|}{ Religion } \\
\hline No religion & 51 & 6.6 \\
\hline Christianity & 615 & 79.3 \\
\hline Islam & 96 & 12.4 \\
\hline Others & 13 & 1.7 \\
\hline \multicolumn{3}{|l|}{ Locality } \\
\hline Agbogbloshie & 107 & 13.8 \\
\hline James town & 215 & 27.7 \\
\hline Ussher town & 453 & 58.5 \\
\hline \multicolumn{3}{|l|}{ Age } \\
\hline $15-24$ & 285 & 36.8 \\
\hline $25-34$ & 236 & 30.4 \\
\hline $35-44$ & 152 & 19.6 \\
\hline $45-59$ & 102 & 13.2 \\
\hline \multicolumn{3}{|l|}{ Occupation } \\
\hline No occupation & 14 & 2.5 \\
\hline Professionals & 67 & 11.9 \\
\hline Skilled manual & 126 & 22.4 \\
\hline Sales/service & 283 & 50.3 \\
\hline Others & 73 & 12.9 \\
\hline \multicolumn{3}{|l|}{ Marital status } \\
\hline Never married & 316 & 40.7 \\
\hline Currently married & 336 & 43.4 \\
\hline Formerly married & 123 & 15.9 \\
\hline \multicolumn{3}{|l|}{ Ethnicity } \\
\hline Akan & 185 & 23.9 \\
\hline Ga-Dangme & 468 & 60.4 \\
\hline Ewe & 56 & 7.2 \\
\hline Others & 66 & 8.5 \\
\hline
\end{tabular}

JHS, Junior High School.

\section{RESULTS}

\section{Background characteristics}

The mean age of the participants was $30.3 \pm 10.8$ years and the highest proportion $(36.8 \%$ ) was $15-24$ years (table 2 ). Close to 6 out of $10(58.5 \%)$ lived in Ussher town. More than half of the respondents $(56.0 \%)$ were women. With regards to educational attainment, the highest proportion $(42.7 \%)$ had middle/JHS education; about onethird $(33.8 \%)$ had secondary/higher education and less one-tenth $(7.0 \%)$ had no education. Majority were
Table 3 Health profiles

\begin{tabular}{lcc}
\hline Smoking status & Number & Percentage \\
\hline $\begin{array}{l}\text { Chronic diseases* } \\
\text { Yes }\end{array}$ & 159 & 20.5 \\
\hline No & 616 & 79.5 \\
\hline $\begin{array}{l}\text { Smoking status } \\
\text { Nonsmokers }\end{array}$ & 719 & 92.8 \\
\hline Smokers & 56 & 7.2 \\
\hline Alcohol & & \\
\hline Yes & 277 & 52.4 \\
\hline No & 252 & 47.6 \\
\hline $\begin{array}{l}\text { Physical activity } \\
\text { No }\end{array}$ & \\
\hline$<3$ times a week & 608 & 78.5 \\
\hline Three or more times a week & 97 & 11.6 \\
\hline Self-rated fat Intake & & 9.9 \\
\hline Low & 197 & 25.5 \\
\hline Medium & 448 & 57.9 \\
\hline High & 129 & 16.6 \\
\hline Self-reported health & & \\
\hline Poor & 89 & 11.8 \\
\hline Good & 39.7 \\
\hline Excellent/very good & 366 & 48.5 \\
\hline
\end{tabular}

${ }^{*}$ Chronic diseases: hypertension (17.4\%), diabetes (5.9\%), asthma $(3.1 \%)$, stroke $(2.3 \%)$, heart disease $(0.4 \%)$, arthritis $(0.3 \%)$, high blood cholesterol $(0.3 \%)$, kidney disease $(0.3 \%)$.

Christians (79.3\%), slightly more than half (50.3\%) were in sales-related jobs and only $2.5 \%$ had no occupation. The highest proportion was currently married $(43.4 \%)$. Slightly more than $60 \%$ were Ga-Dangme, $23.9 \%$ were Akan, Ewe $(7.2 \%)$ and $8.5 \%$ belonged to other ethnic groups such as Guan, Gruma, Mole-Dagbani and Grussi, Mande.

\section{Health profiles}

Table 3 shows that about one-fifth $(20.5 \%)$ of the respondents were living with at least one chronic disease (hypertension-17.4\%, diabetes-5.9\%, asthma-3.1\%, stroke $-2.3 \%$, heart disease $-0.4 \%$, arthritis- $0.3 \%$, high blood cholesterol- $0.3 \%$ and kidney disease-0.3\%). Less than one-tenth $(7.2 \%)$ were smokers, more than half (52.4\%) were current consumers of alcohol and about one-tenth $(9.9 \%)$ engaged in physical activity three or more times a week. More than half $(57.9 \%)$ reported that their diet in the last 12 months was medium in fat and $16.6 \%$ consumed foods that were high in fat within this period. With regards to self-reported health, more than 4 out of 10 rated their health as excellent and slightly more than 1 out of 10 rated their health as poor $(48.5 \%$ and $11.8 \%$, respectively). 


\begin{tabular}{|c|c|c|}
\hline Sources of knowledge & Number & Percentage \\
\hline Radio & 224 & 28.9 \\
\hline Television & 148 & 19.1 \\
\hline Friends/relatives & 107 & 13.8 \\
\hline School/teachers & 53 & 6.8 \\
\hline Health workers & 51 & 6.6 \\
\hline Other sources & 43 & 5.6 \\
\hline Multiple sources & 149 & 19.2 \\
\hline Total & 775 & 100.0 \\
\hline
\end{tabular}

CVD, cardiovascular disease.

With respect to sources of CVD knowledge, almost a third of participants $(28.9 \%)$ had heard of CVD from the radio, $19.1 \%$ from television, $13.8 \%$ from friends and relatives, $6.6 \%$ from health workers and $19.2 \%$ from multiple sources (table 4 ).

\section{Cardiovascular disease knowledge}

The mean knowledge score was $19.3 \pm 4.8$ (table 5). With respect to CVD risk factors, majority of the respondents $(92.8 \%)$ knew that cigarette smoking increased the risk of CVD while eating fruit and vegetables everyday, and regular exercises could reduce the risk of the disease. However, less than half linked fatty foods to increase in blood cholesterol levels. Also, about $46.0 \%$ said that CVD could not be affected by heavy alcohol use and slightly more than half $(50.2 \%)$ agreed that family history constituted CVD risk. The results further showed that knowledge on CVD symptoms was low. Specifically, less than $60 \%$ knew that shortness of breath was a sign of CVD and slightly more than half attributed feelings of chest pain or discomfort to CVD symptoms. With respect to CVD prevention, treatment and control, $72.0 \%$ said that keeping blood pressure under control reduces risk of heart disease; more than half $(55.9 \%)$ mentioned that people with high blood pressure need to use blood pressure medicine for life. Also, less than half $(46.8 \%)$ said that taking a blood pressure medicine for 1 month can cure and more than 4 out of $10(43.0 \%)$ said that blood pressure should be checked only when people have chest pain or headaches. Overall, about $71.1 \%$ of the respondents had good CVD knowledge, 20.5\% had moderate CVD knowledge and less than one-tenth (8.4\%) had poor CVD knowledge.

\section{Determinants of CVD knowledge}

Table 6 shows that ethnicity, alcohol consumption, self-reported health and sources of CVD knowledge were determinants of CVD knowledge. Those who were Akan had more CVD knowledge than the Ga-Dangme ( $\beta=2.98$, $\mathrm{p}<0.01)$; however, CVD knowledge was not significantly different among those who were Ewe, Ga-Dangme and those who belonged to other ethnic groups. CVD knowledge was higher among those who were current consumers of alcohol compared with their counterparts $((\beta=1.82, p<0.05)$. Those who rated their health as very good/excellent had more CVD knowledge than those who rated their health as poor. Those who received CVD information from health workers and multiple sources significantly had lower CVD knowledge than those who received CVD information from the radio $((\beta=-4.26$, $\mathrm{p}<0.05 ; \beta=-5.10, \mathrm{p}<0.01$, respectively).

\section{DISCUSSION}

Our study showed that knowledge of CVD risk factors and CVD symptoms was low among the participants. The determinants of CVD knowledge included ethnicity, alcohol consumption, self-reported health and sources of CVD knowledge. CVD knowledge was highest among a minority Akan ethnic group, those who were current consumers of alcohol, those who rated their health as very good or excellent and those who received CVD information from other sources other than television, radio, school and health workers.

The study communities are made up of predominantly lower socioeconomic status (SES) individuals. Research in Cameroon, Canada, India and Japan showed that people with low SES have poor knowledge of CVD because they are less likely to get access to educational or informational material about CVD and other health issues. $^{29-32}$ As is often characteristic of low-income settings, and particularly for this study's setting, the environment is obesogenic, consumption of healthy foods is low, few individuals engage in health-enabling habits (eg, physical activity, moderate alcohol consumption) and health-seeking behaviours are poor. ${ }^{33-36}$ There is also the tendency to get health information and advice from friends, relatives or peers, to self-medicate, and to healershop across biomedical and alternative health systems. ${ }^{1837}$ This combination of factors is implicated in a person's risk of developing CVD and its complications. Crucially, early recognition of CVD symptoms is an important step that must occur before treatment can be obtained, and individuals' inability to recognise the symptoms of CVD may contribute to delay in presentation to hospital for early diagnosis and treatment and poor prognosis. ${ }^{17}{ }^{20}$ Late presentation of serious conditions is common in Ghana and has been implicated in poor prognosis for cancers. ${ }^{38}$

With respect to the determinants of CVD knowledge, our study showed that age was not a determinant of CVD knowledge among the respondents. Some studies have shown that older people living with cardiovascular disease have more opportunities to access information about CVD. ${ }^{39}$ Other studies have reported either no age-related associations or inverse relationship between age and CVD knowledge. ${ }^{29}{ }^{40}$ The present findings raise a cause for concern because CVD knowledge was low among the youths, even though research in Africa has shown an increase in incidence of CVD in this age group..$^{131441}$ Also, CVD risk is reported to be high among youth in the study communities and youth engage in limited physical activity 


\begin{tabular}{|c|c|c|}
\hline & Knowledge area & Correct responses (\%) \\
\hline & \multicolumn{2}{|l|}{ CVD risks } \\
\hline 1 & Heart disease can be prevented & 84.0 \\
\hline 2 & Cigarette smoking can cause heart disease and stroke & 92.8 \\
\hline 3 & There is greater risk for heart disease in elderly & 80.9 \\
\hline 4 & People with high blood pressure should avoid salt in their diets. & 78.5 \\
\hline 5 & If people quit smoking it reduces the risk of heart disease & 88.9 \\
\hline 6 & Salty food makes causes high blood pressure & 74.6 \\
\hline 7 & High blood pressure is a risk factor for heart disease & 74.1 \\
\hline 8 & Fatty foods do not increase blood cholesterol levels & 48.5 \\
\hline 9 & More than three meals per week of red meat is not good for your health & 67.5 \\
\hline 10 & Eating fruit and vegetables every day is beneficial & 93.0 \\
\hline 11 & Overweight people are more likely to have heart disease & 75.5 \\
\hline 12 & Regular exercise reduces risk of heart disease & 90.8 \\
\hline 13 & Regular walking can reduce risk of heart disease & 88.5 \\
\hline 14 & Stress and sadness increase the risk of heart disease & 78.8 \\
\hline 15 & Under stressful situations, blood pressure will increase & 80.5 \\
\hline 16 & Heavy alcohol use does not affect your blood pressure. & 45.8 \\
\hline 17 & High cholesterol is a risk factor for heart disease & 67.6 \\
\hline 18 & Diabetes is a risk factor for heart disease & 62.8 \\
\hline \multirow[t]{2}{*}{19} & Heart disease in your family will increase your risk of heart disease & 50.2 \\
\hline & \multicolumn{2}{|l|}{ CVD symptoms } \\
\hline 20 & Shortness of breath may be a sign of heart disease. & 59.4 \\
\hline \multirow[t]{2}{*}{21} & Feeling chest pain or discomfort can be a sign of heart disease & 52.5 \\
\hline & \multicolumn{2}{|l|}{ CVD prevention, treatment and control } \\
\hline 22 & To keep blood pressure under control will reduce the risk of heart disease & 76.8 \\
\hline 23 & People with high blood pressure need to use blood pressure medicine for life & 55.9 \\
\hline 24 & People with high cholesterol need to take medication & 72.0 \\
\hline 25 & People with diabetes need to control sugar intake & 91.9 \\
\hline 26 & People should only get their blood pressure checked if they have chest pain or headaches & 43.0 \\
\hline \multirow[t]{2}{*}{27} & If you have high blood pressure taking a medicine for 1 month can cure you & 46.8 \\
\hline & Knowledge score (mean and SD) & $19.3(4.8)$ \\
\hline
\end{tabular}

Good CVD knowledge (71.1\%), moderate CVD knowledge (20.5\%) and poor CVD knowledge (8.4\%)

.CVD, cardiovascular disease.

and other risk protective behaviours. ${ }^{35}$ There is, therefore, a need to improve public knowledge of CVD, especially among the youth with an overall goal of promoting lifestyle changes before disease progression occurs; this may help to reduce the incidence of CVD among youth and older community members.

There was no significant difference in CVD knowledge between those who were living with at least one chronic condition and those without chronic disease. While people living with chronic conditions were expected to have experiential knowledge of the conditions, due to more regular interactions with healthcare professionals, the data also showed that only $6.6 \%$ of participants received CVD knowledge from health workers. This raises questions about whether people living with CVD get general or personalised information and counselling on the treatment/management of the condition. The current evidence suggests that Ghana's health system's responses to non-communicable diseases (NCDs) have not been comprehensive or integrated..$^{42}$ Within the study communities, previous research suggests that community health workers have poor CVD knowledge. ${ }^{19}$ This lack of knowledge is likely to shape the quality and outcome of professional biomedical care. For example, respondents who heard about GVD from health workers had lower CVD knowledge than those who sourced information from radio and television. The mass media plays an important role in disseminating information on chronic diseases 
Table 6 Determinants of CVD knowledge

B $95 \% \mathrm{Cl}$

\begin{tabular}{|c|c|c|}
\hline \multicolumn{3}{|l|}{ Sex } \\
\hline \multicolumn{3}{|l|}{ Female (RC) } \\
\hline Male & 0.21 & -0.69 to 2.11 \\
\hline \multicolumn{3}{|l|}{ Level of education } \\
\hline \multicolumn{3}{|l|}{ No education (RC) } \\
\hline Primary & -1.95 & -5.68 to 1.79 \\
\hline Middle/JHS & -0.97 & -4.39 to 2.44 \\
\hline Secondary and above & 0.57 & -3.14 to 4.28 \\
\hline \multicolumn{3}{|l|}{ Religion } \\
\hline \multicolumn{3}{|l|}{ No religion/others $(\mathrm{RC})$} \\
\hline Christianity & 0.59 & -2.88 to 2.55 \\
\hline Islam & 0.38 & -3.57 to 4.76 \\
\hline \multicolumn{3}{|l|}{ Locality } \\
\hline \multicolumn{3}{|l|}{ Agbogbloshie (RC) } \\
\hline James town & 0.38 & -2.50 to 3.26 \\
\hline Ussher town & 0.26 & -2.41 to 2.93 \\
\hline \multicolumn{3}{|l|}{ Age } \\
\hline \multicolumn{3}{|l|}{$15-24(\mathrm{RC})$} \\
\hline $25-34$ & 1.94 & -0.50 to 4.37 \\
\hline $35-44$ & 0.67 & -2.06 to 3.40 \\
\hline $45-59$ & 1.61 & -1.53 to 4.74 \\
\hline
\end{tabular}

Occupation

\begin{tabular}{|c|c|c|}
\hline \multicolumn{3}{|l|}{ No occupation (RC) } \\
\hline Professionals & -0.79 & -6.78 to 5.19 \\
\hline Skilled manual & -1.73 & -7.62 to 4.16 \\
\hline Sales/service & -2.77 & -8.44 to 2.91 \\
\hline Others & 0.13 & -5.95 to 5.98 \\
\hline \multicolumn{3}{|l|}{ Marital status } \\
\hline \multicolumn{3}{|l|}{ Never married (RC) } \\
\hline Currently married & 0.18 & -0.55 to 0.91 \\
\hline Formerly married & 1.42 & -1.30 to 4.14 \\
\hline \multicolumn{3}{|l|}{ Ethnicity } \\
\hline \multicolumn{3}{|l|}{ Ga-Dangme (RC) } \\
\hline Akan & $2.98^{\star \star}$ & 0.83 to 5.12 \\
\hline Ewe & -098 & -4.23 to 2.28 \\
\hline Others & -0.71 & -4.79 to 3.37 \\
\hline \multicolumn{3}{|l|}{ Chronic diseases } \\
\hline \multicolumn{3}{|l|}{ No $(R C)$} \\
\hline Yes & 1.51 & -0.64 to 3.66 \\
\hline \multicolumn{3}{|l|}{ Smoking status } \\
\hline \multicolumn{3}{|l|}{ Nonsmokers (RC) } \\
\hline Smokers & -1.24 & -3.89 to 1.41 \\
\hline \multicolumn{3}{|l|}{ Alcohol } \\
\hline \multicolumn{3}{|l|}{ No (RC) } \\
\hline Yes & $1.82^{*}$ & -0.10 to 3.54 \\
\hline Physical activity & & \\
\hline
\end{tabular}

Continued
Table 6 Continued

$\beta$

$95 \% \mathrm{Cl}$

\section{No (RC)}

$<3$ times a week

$-1.24$

-3.85 to 1.36

Three or more times a -1.24

-4.17 to 1.69

week

Self-reported health

\begin{tabular}{lll} 
Poor (RC) & \\
Good & $2.70^{\star}$ & 0.08 to 5.31 \\
\hline Excellent/very good & $3.81^{\star *}$ & 1.08 to 6.55
\end{tabular}

Self-rated fat Intake

\begin{tabular}{lll} 
Low $(\mathrm{RC})$ & & \\
Middle & -1.84 & -3.85 to 1.37 \\
\hline High & -2.31 & -4.83 to -0.21 \\
\hline Sources of Knowledge & & \\
$\quad$ Radio $(\mathrm{RC})$ & & \\
Television & -0.54 & -3.39 to 2.31 \\
Friends/relatives & -1.11 & -3.72 to 1.49 \\
\hline School/teachers & -2.89 & -7.92 to 2.14 \\
Health workers & $-4.26^{*}$ & -7.92 to -0.61 \\
\hline Other sources & 2.76 & -1.19 to 6.70 \\
Multiple sources & $-5.10^{* *}$ & -8.11 to -2.09 \\
\hline
\end{tabular}

${ }^{*} \mathrm{P}<0.05,{ }^{* *} \mathrm{P}<0.01,{ }^{* * *} \mathrm{P}<0.001 ; \mathrm{F}=2.38^{* * *}$, Adj $\mathrm{R}^{2}=10.8 \%$ JHS, Junior High School.

in Ghana and radio is a popular source of information for many Ghanaians. ${ }^{43}$ However, the content of media reportage on NCDs is drawn from disparate national and international sources and might be inaccurate or irrelevant to the Ghanaian sociocultural setting. ${ }^{43}$ Therefore, while radio has wider coverage for disseminating CVD information in the study communities, compared with health workers, the content of information might be as problematic as that from community health workers who have poor CVD knowledge.

\section{Limitations}

This study has four key limitations. First, participants' responses on sources of CVD knowledge may have been affected by recall bias. Second, the lower scores for items under CVD symptoms and some other items may be due to inadequate community-based CVD prevention programmes in these communities and the country at large. Furthermore, the CVD knowledge scale has an imbalance between scale-item weight and the incidence of existing risk factors of CVD in Ghana. For instance, only one question was asked about overweight even though evidence shows that overweight/obesity is an increasing public health challenge in the country. Finally, we measured physical activity as the number of days respondents spent doing moderate-intensity activities including sports, fitness or recreational leisure activities. Based on this, $21.5 \%$ of the study participants 
were partially or fully active compared with $22.4 \%$ of participants who had skilled manual occupation. This discrepancy may be because we used moderate-intensity activities as proxies for physical activity and this measure did not take into account other forms of physical activity such as those associated with skilled manual occupation. This may have led to an underestimation of physically active participants in this study. Despite these limitations, this study provides an important overview of CVD knowledge in three urban poor communities in Accra and the findings are generalisable to the three study communities.

\section{CONCLUSION}

This study examined the level and determinants of CVD knowledge in three urban poor communities in Accra, Ghana. The results suggest that there is an urgent need for CVD education in these communities, in order to promote prevention and management of this condition. Presently, Ghana's health system is weak and not NCD competent. Our findings suggest that people are not drawing knowledge from health workers but from social networks and the mass media. A key strategy will be to invest in health systems strengthening: existing initiatives that aim to enhance universal health coverage such as Community-Based Health Planning and Services (CHPS) and the National Health Insurance Scheme (NHIS) can be leveraged for community-based CVD prevention and control. ${ }^{19}$ Under the CHPS programme, community health workers (CHWs) have been trained to provide care for general and reproductive health problems; they can equally be trained to provide diagnostic and primary care services for CVD. ${ }^{19}$ The NHIS can be expanded to include provision of NCD medicines and technologies (eg, laboratory tests, blood glucose metres, blood pressure monitors) in primary care facilities to improve early detection, treatment and continuity of care.

Successful CVD intervention programmes in LMICs incorporate task shifting approaches, public health and peer education and training of healthcare and allied professionals. ${ }^{11}$ A second strategy will be to build capacity at the community level to improve knowledge and healthprotective practices. The mass media and social and religious networks are major sources of health, illness, CVD and NCD knowledge for the study communities. ${ }^{19}$ Mass media sources can be improved through training of journalists and developing task-shifting strategies in social and faith-based spaces. ${ }^{43}$ Faith-based organisations in the study communities provide health programmes for congregants and also involve non-health professionals in their healthcare activities. ${ }^{24}$ CHWs can be trained to deliver information, screening and support services in these spaces. Finally, establishing and supporting CVD patient groups can empower individuals living with $\mathrm{CVD}^{37} 43$ as well as create powerful platforms for patient-led CVD advocacy for the wider community.
Contributors OAS and AdGA conceptualised the study. MKK drafted the background section. OAS analysed the data. OAS and CA drafted the results, discussion and conclusion sections. RBA and PYA assisted with data analysis and draft of results. AdGA led and supervised the interpretation of the data and writing of the manuscript. All authors read and approved the final manuscript. OAS and AdGA are responsible for the overall content as the guarantors.

Funding Funding for the Urban Health and Poverty project, the data source of this study, was provided by the William and Flora Hewlett Foundation (Grant recipient: Professor Francis Nii Amoo Dodoo; Grant number: 2010-5305), the International Development Research Centre (IDRC) (Grant recipient: Professor Samuel Nii Ardey Codjoe; Grant number: 106548-001), and University of Ghana Office of Research, Innovation and Development (Grant recipient: Professor Ama de-Graft Aikins; Grant number: LMG-005-FSS)

Competing interests None declared.

Patient and public involvement Patients and/or the public were not involved in the design, or conduct, or reporting, or dissemination plans of this research.

Patient consent for publication Not applicable.

Ethics approval Ethical approval for the study was obtained from the Noguchi Memorial Institute for Medical Research-Institutional Review Board in August 2013 (certified protocol number 105/12-13). Written informed consent was sought from participants prior to their inclusion in the study.

Provenance and peer review Not commissioned; externally peer reviewed.

Data availability statement Data are available upon reasonable request. The datasets used and/or analysed for this study are not available on a public repository as they contain identifiable and sensitive information making it impossible to protect participants' confidentiality. Researchers interested in accessing this data may contact the corresponding author.

Open access This is an open access article distributed in accordance with the Creative Commons Attribution Non Commercial (CC BY-NC 4.0) license, which permits others to distribute, remix, adapt, build upon this work non-commercially, and license their derivative works on different terms, provided the original work is properly cited, appropriate credit is given, any changes made indicated, and the use is non-commercial. See: http://creativecommons.org/licenses/by-nc/4.0/.

ORCID iD

Olutobi Adekunle Sanuade http://orcid.org/0000-0003-4972-1098

\section{REFERENCES}

1 Global atlas on cardiovascular disease prevention and control, 2019. Available: http://www.who.int/cardiovascular_diseases/en/ [Accessed 30 Aug 2019].

2 Cardiovascular diseases (CVDs): key facts, 2021. Available: https:// www.who.int/news-room/fact sheets/detail/cardiovascular-diseases(cvds) [Accessed 02 Aug 2021].

3 Yach D, Hawkes C, Gould CL, et al. The global burden of chronic diseases: overcoming impediments to prevention and control. JAMA 2004;291:2616-22.

4 BeLue R, Okoror TA, Iwelunmor J, et al. An overview of cardiovascular risk factor burden in sub-Saharan African countries: a socio-cultural perspective. Global Health 2009;5:10.

5 Aikins AdeG, de-Graft AikinsA, AgyemangC. Chronic noncommunicable diseases in low- and middle-income countries: concepts and strategies for prevention, control and advocacy. $C A B$ Rev 2017;12.

6 Sanuade OA, Anarfi JK, Aikins Ade-G, de-Graft AikinsA, et al. Patterns of cardiovascular disease mortality in Ghana: a 5-year review of autopsy cases at Korle-Bu teaching hospital. Ethn Dis 2014;24:55-9.

7 Capewell S, Graham H. Will cardiovascular disease prevention widen health inequalities? PLoS Med 2010;7:e1000320.

8 Unal B, Critchley JA, Capewell S. Modelling the decline in coronary heart disease deaths in England and Wales, 1981-2000: comparing contributions from primary prevention and secondary prevention. BMJ 2005;331:614-7.

9 Alston LV, Peterson KL, Jacobs JP, et al. A systematic review of published interventions for primary and secondary prevention of ischaemic heart disease (IHD) in rural populations of Australia. BMC Public Health 2016;16:895.

10 Kivimäki M, Shipley MJ, Ferrie JE, et al. Best-practice interventions to reduce socioeconomic inequalities of coronary heart disease 
mortality in UK: a prospective occupational cohort study. The Lancet 2008;372:1648-54.

11 van de Vijver S, Oti S, Addo J, et al. Review of community-based interventions for prevention of cardiovascular diseases in low- and middle-income countries. Ethn Health 2012;17:651-76.

12 Emberson J, Whincup P, Morris R, et al. Evaluating the impact of population and high-risk strategies for the primary prevention of cardiovascular disease. Eur Heart J 2004;25:484-91.

13 Addo J, Smeeth L, Leon DA. Hypertension in sub-Saharan Africa: a systematic review. Hypertension 2007;50:1012-8.

14 Mensah GA. Epidemiology of stroke and high blood pressure in Africa. Heart 2008;94:697-705.

15 Jafary FH, Aslam F, Mahmud $\mathrm{H}$, et al. Cardiovascular health knowledge and behavior in patient attendants at four tertiary care hospitals in Pakistan - a cause for concern. BMC Public Health 2005;5:124-32.

16 de-Graft Aikins A, Unwin N, Agyemang C, et al. Tackling Africa's chronic disease burden: from the local to the global. Global Health 2010;6:5.

17 Chow C-M, Chu JY, Tu JV, et al. Lack of awareness of heart disease and stroke among Chinese Canadians: results of a pilot study of the Chinese Canadian cardiovascular health project. Can J Cardiol 2008;24:623-8.

18 Awuah RB, Anarfi JK, Agyemang C, et al. Prevalence, awareness, treatment and control of hypertension in urban poor communities in Accra, Ghana. J Hypertens 2014;32:1203-10.

19 de-Graft Aikins A, Kushitor M, Koram K, et al. Chronic noncommunicable diseases and the challenge of universal health coverage: insights from community-based cardiovascular disease research in urban poor communities in Accra, Ghana. BMC Public Health 2014:14:S3-11.

20 Schneider AT, Pancioli AM, Khoury JC, et al. Trends in community knowledge of the warning signs and risk factors for stroke. JAMA 2003;289:343-6.

21 Von ElmE, AltmanDG, EggerM. The strengthening the reporting of observational studies in epidemiology (STROBE) statement: guidelines for reporting observational studies. UroToday Int $J$ 2009;2:20-2.

22 Greif MJ, Nii-Amoo Dodoo F. How community physical, structural, and social stressors relate to mental health in the urban slums of Accra, Ghana. Health Place 2015;33:57-66.

23 Arikanl, MetintasS, KalyononcuC. The cardiovascular disease risk factors knowledge level (CARRF-KL) scale: a validity and reliability study Ölçeai'nin geçerlik ve güvenirliai. Türk Kardiyol Dern Arfl -Arch Turk Soc Cardiol 2009;37:35-40.

24 Abanilla PKA, Huang K-Y, Shinners D, et al. Cardiovascular disease prevention in Ghana: feasibility of a faith-based organizational approach. Bull World Health Organ 2011;89:648-56.

25 Amadi CE, Lawal FO, Mbakwem AC, et al. Knowledge of cardiovascular disease risk factors and practice of primary prevention of cardiovascular disease by community pharmacists in Nigeria: a cross-sectional study. Int J Clin Pharm 2018;40:1587-95.

26 Sanuade OA, Dodoo FN-A, Koram K, et al. Prevalence and correlates of stroke among older adults in Ghana: evidence from the study on global ageing and adult health (SAGE). PLoS One 2019;14:e0212623.
27 Gago CM, Lopez-Cepero A, O'Neill J, et al. Association of a singleitem self-rated diet construct with diet quality measured with the alternate healthy eating index. Front Nutr 2021;8:1-9.

28 Adjoian TK, Firestone MJ, Eisenhower D, et al. Validation of self-rated overall diet quality by healthy eating index-2010 score among New York City adults, 2013. Prev Med Rep 2016;3:127-31.

29 Aminde LN, Takah N, Ngwasiri C, et al. Population awareness of cardiovascular disease and its risk factors in Buea, Cameroon. BMC Public Health 2017;17:1-10.

30 Potvin L, Richard L, Edwards AC. Knowledge of cardiovascular disease risk factors among the Canadian population: relationships with indicators of socioeconomic status. CMAJ 2000;162:S5-11.

31 Justin Zaman M, Patel A, Jan S, et al. Socio-economic distribution of cardiovascular risk factors and knowledge in rural India. Int $J$ Epidemiol 2012;41:1302-14.

32 Tsuji M, Arima H, Ohkubo T, et al. Socioeconomic status and knowledge of cardiovascular risk factors: nippon DATA2010. $J$ Epidemiol 2018;28 Suppl 3:S46-52.

33 Dake FAA, Thompson AL, Ng SW, et al. The local food environment and body mass index among the urban poor in Accra, Ghana. $J$ Urban Health 2016;93:438-55.

34 Boatemaa S, Badasu DM, de-Graft Aikins A. Food beliefs and practices in urban poor communities in Accra: implications for health interventions. BMC Public Health 2018;18:434.

35 Afrifa-Anane E, Agyemang C, Codjoe SNA, et al. The association of physical activity, body mass index and the blood pressure levels among urban poor youth in Accra, Ghana. BMC Public Health 2015; $15: 269$

36 Da Pilma Lekettey J, Dako-Gyeke P, Agyemang SA, et al. Alcohol consumption among pregnant women in James town community, Accra, Ghana. Reprod Health 2017;14:1-9.

37 de-Graft Aikins A, Kushitor M, Kushitor SB. Building cardiovascular disease competence in an urban poor Ghanaian community: a social psychology of participation approach. J Community Appl Soc Psychol 2020.

38 Dedey F, Wu L, Ayettey H, et al. Factors associated with waiting time for breast cancer treatment in a teaching hospital in Ghana. Health Educ Behav 2016;43:420-7.

39 Awad A, Al-Nafisi H. Public knowledge of cardiovascular disease and its risk factors in Kuwait: a cross-sectional survey. BMC Public Health 2014;14:1-11.

40 Boateng D, Wekesah F, Browne JL, et al. Knowledge and awareness of and perception towards cardiovascular disease risk in sub-Saharan Africa: a systematic review. PLoS One 2017;12:e0189264-21.

41 Kengne AP, Mayosi BM. A snapshot of cardiovascular diseases in Africa in the new millennium. Cardiovasc J Afr 2013;24:104-5.

42 de-Graft Aikins A, Koram K. Health and healthcare in Ghana, 19572017. In: Aryeetey E, Kanbur R, eds. The economy of Ghana: sixty years after independence. Oxford University Press, 2017.

43 de-Graft Aikins A, Boynton P, Atanga LL. Developing effective chronic disease interventions in Africa: insights from Ghana and Cameroon. Global Health 2010;6:6-8. 